\title{
Modeling and Optimization of Pulling Point Position of Luffing Jib on Portal Crane
}

\author{
Qianqian Jiao, ${ }^{1}$ Yixiao Qin $\mathbb{D D}^{1}{ }^{1}$ Yuehuang Han, ${ }^{2}$ and Jinpeng Gu ${ }^{1}$ \\ ${ }^{1}$ School of Mechanical Engineering, Taiyuan University of Science and Technology, Taiyuan 030024, China \\ ${ }^{2}$ Sunny Optical Technology (Group) Company Limited, Ningbo 315211, China \\ Correspondence should be addressed to Yixiao Qin; 1983015@tyust.edu.cn
}

Received 21 July 2020; Accepted 17 March 2021; Published 8 April 2021

Academic Editor: Yumin Cheng

Copyright (C) 2021 Qianqian Jiao et al. This is an open access article distributed under the Creative Commons Attribution License, which permits unrestricted use, distribution, and reproduction in any medium, provided the original work is properly cited.

Portal crane is the most commonly used equipment for cargo handling of large mixed loading ships with its advantages of flexible and convenient operation, wide adaptability, and high loading and unloading efficiency. The reasonable modeling and optimization of the pulling point position of luffing jib of portal crane can reduce the rack force of portal crane and the power consumption output of the rack and pinion during the luffing process. Based on penalty function optimization, the interior point method is used to optimize the pulling point position of luffing jib. Compared with the initial design, the race force of the luffing jib is reduced to a certain extent. In addition, the consistency between the finite element analysis results and the optimization results can be verified, and the effectiveness of the optimization design is also proved through the finite element analysis of portal crane.

\section{Introduction}

Portal crane promotes the development of international logistics industry, and the demand of port handling in international logistics industry is also increasing. The increasing demand of portal crane in port handling also puts forward higher requirements for the operation performance and precision manufacturing of portal crane. At present, as the luffing system of crane, most of schemes of portal crane jib system adopt the horizontal luffing system, which makes the lifted weight move approximately horizontally in the process of luffing. The live counterweight behind the herringbone frame is used to balance the lifting weight so that crane can carry out luffing operation with lower driving force. The reasonable optimization design of rack pulling point position can reduce the driving force required by crane luffing operation and the power consumption output of rack and pinion work.

The mixed penalty function is adopted to optimize the upper structure of jib cranes, which realizes the reduction in maximum luffing resistance moment and moment of force during crane operation [1]. The vibration testing technology is added to the fault diagnosis technology of portal crane, and the vibration testing and modal analysis of portal crane are carried out by using environmental vibration modal analysis in order to improve the safety and reliability of portal crane [2]. The transient dynamic simulation on the arm frame structure of crane is carried out, and the dynamic response of the arm frame is obtained at the same time [3]. The optimization design of the luffing mechanism is carried out, and the design scheme is formulated according to its characteristics, which achieves considerable optimization effect [4]. The optimization design of the four-bar luffing mechanism of portal crane is carried out by the method of combining genetic algorithm and finite element analysis to improve the design quality [5]. The electromechanical coupling dynamics of portal crane hoisting system is studied, and the electromechanical coupling model of portal crane hoisting system is established, which provides theoretical reference and basis for the matching and optimization of its electromechanical system parameters [6]. The spreader rotating parts of portal crane are studied, and the concept of skew angle control is proposed, which is successfully applied to port crane [7]. 
The deformation and stress distribution of portal crane trunk girder are analyzed by the finite element analysis method, and some reasonable suggestions and methods for structural optimization are given [8]. The BP neural network algorithm is used to calculate the lifting weight of portal crane and the instantaneous output power of lifting motor, and its effectiveness is proved by experiments [9]. The seismic performance of port quayside crane can be analyzed by a nonlinear static analysis method [10]. The braking process of portal crane under the action of pulsating wind is simulated, and the windproof effect of its windproof brake under complex wind load is analyzed [11]. Topology and shape optimization can be used to design the structure of mobile port crane [12]. A new three-dimensional position control scheme for mobile port crane is proposed, which can be used for the sway control in the process of cargo lifting [13]. A portal crane model is established through SolidWorks, and Adams software is used to obtain the dynamic characteristics of hinge point force in the process of crane luffing process [14]. A simulation experiment platform of port portal crane is established based on virtual technology [15]. The research process of this paper is also inspired by the relevant previous results [16-22].

Numerical calculations are widely used in scientific research and engineering applications [23-25], which can realize optimal design and high-precision analysis of structures. A new and effective numerical method developed in recent years is the meshless method, including diffuse element method [26], smoothed particle method [27], reproducing kernel particle method [28-31], elementfree Galerkin method [32-41], finite point method [42], natural element method [43], radial basis function method [44], mesh-free kp-Ritz method [45], complex variable meshless method [46-48], and all kinds of meshless boundary integral equation method [49-51]. In addition, numerical methods also include weighted residual method, finite difference method, finite element method, and boundary element method. The finite element method adopted in this paper is one of the most widely used methods with the advantages of simple, intuitive, and high calculation efficiency.

Here, the penalty function method based on the interior point method is used to optimize the position of the rack pulling point of the portal crane so that the driving force required by the rack when the portal crane is hoisted and luffing is reduced to a lower value, and at the same time, the luffing mechanism is more energy-saving and environmentfriendly. In addition, the finite element model of portal crane is built and analyzed. By comparing the finite element analysis results with the optimization results, the feasibility and accuracy of the optimization of the rack pulling point of portal crane can be verified.

\section{Principle of Penalty Function Optimization Algorithm}

2.1. Penalty Function Method. The basic idea of penalty function method is to construct a new objective function by combining the objective function and all constraint functions in the constrained optimization problem to solve the constrained optimization problem.

For constrained optimization problem,

$$
\begin{array}{ll}
\min & f(x), x \in R^{n} \\
\text { s.t. } & g_{u}(x) \leq 0, u=1,2, \ldots, q, \\
& h_{v}(x) \leq 0, v=1,2, \ldots, p<n .
\end{array}
$$

Penalty function method constructs the following function:

$$
\varphi(\mathbf{x}, r)=f(\mathbf{x})+r P(\mathbf{x}),
$$

where $P(\mathbf{x})$ is some form of universal function defined by all constraint functions $g_{u}(\mathbf{x})$ and $h_{v}(\mathbf{x}) ; r$ is the penalty factor that varies according to a given rule; and $r P(\mathbf{x})$ is the penalty term, whose function is to promote the optimal solution to the feasible solution.

Penalty function method transforms the original constrained optimization problem into unconstrained optimization problem, that is,

$$
\min \{\varphi(\mathbf{x}, r)=f(\mathbf{x})+r P(\mathbf{x})\} .
$$

When the iteration point violates the constraint conditions, the value of the $r P(\mathbf{x})$ term becomes larger to urge the iteration point to move only in the direction of satisfying the constraint conditions.

2.2. Interior Point Penalty Function Method. Interior point method is to define the new objective function in the feasible region so that its initial point and iteration point meet the requirement of existing in the feasible region.

Its constraint function $P(\mathbf{x})$ is constructed as

$$
P(\mathbf{x})=-\sum_{u=1}^{q} \frac{1}{g_{u}(\mathbf{x})} .
$$

The penalty factor $r$ should satisfy $c$ and

$$
\lim _{k \longrightarrow \infty} r^{(k)}=0 \text {. }
$$

Therefore, the penalty function form of interior point method is

$$
\varphi\left(\mathbf{x}, r^{(k)}\right)=f(\mathbf{x})-r^{(k)} \sum_{u=1}^{q} \frac{1}{g_{u}(\mathbf{x})} .
$$

\section{Mechanical Analysis Model of Rack}

3.1. Live Counterweight Mechanical Model. As shown in Figure 1, the balance weight is calculated according to the balance principle of moving center of gravity, and it can be concluded as

$$
G_{d} \approx \frac{G_{b} h_{b}+\left(G_{x}+1 / 2 G_{l}\right) h_{x}}{h_{d}},
$$

where $G_{d}$ is the balance weight, $G_{b}$ is the weight of arm frame, $G_{l}$ is the weight of large tie rods, $G_{x}$ is the weight of 
the trunk girder, $h_{d}$ is the lifting drop of the balance weight, $h_{b}$ is the lifting drop of the center of gravity of arm frame, and $h_{x}$ is the lifting drop of the trunk girder.

3.2. Calculation of Rack Force F by Mechanical Analysis.
Rack force of portal crane mainly consists of the following aspects:

(1) As shown in Figure 2, rack resistance caused by the weight of the jib system is not fully balanced:

$$
F_{f 1}=\frac{\left(G_{d} r_{d} r_{1} / r_{2}+G_{l i} r_{l i} r_{1} / r_{2}-1 / 2 G_{g} r_{g} r_{1} / r_{2}+1 / 2 G_{g} l_{g}+G_{b} r_{b}+N_{x} r_{x}\right)}{r_{f}}
$$

where $G_{g}$ is the weight of tie rods of the balance system, $G_{l i}$ is the weight of the balance beam, $r_{f}$ is the moment arm of force of rack against the arm frame point $\mathrm{O}$, and $N_{x}$ is the force of $G_{x}+1 / 2 G_{l}$ (i.e., the gravity of large tie rods and trunk girder) to the hinge point.

(2) The rack resistance caused by wind load on the jib system is

$$
F_{f 2}=\frac{p_{x} h_{x}+p_{b} h_{b}}{r_{f}}
$$

where $p_{x}$ is the wind load of trunk girder, $p_{b}$ is the wind load of the arm frame, $h_{x}$ is the moment arm of force of trunk girder against the arm frame point $\mathrm{O}$, and $h_{b}$ is the moment arm of force of wind load against the arm frame point $\mathrm{O}$.

(3) As shown in Figure 3, rack resistance is caused by deflection angle $\alpha$ of the lifting rope to the plumb line due to wind load acting on the jib system, centrifugal force and luffing of the jib system during rotation, inertial force caused by the article during rotation, and braking during operation:

$$
F_{f 3}=\frac{H h_{a}}{r_{f}},
$$

where $H$ is the resultant force of the horizontal force and the resulting large pull rods force $S_{T}$ which acts on the hinge point like trunk girder and arm frame, $h_{a}$ is the moment arm of force of resultant force $H$ to the lower hinge point of the arm frame, and $P_{Q}$ is the weight load.

Finally, it is concluded that the rack force $F$ is

$$
F=-\left(F_{f 1}+F_{f 2}+F_{f 3}\right) \text {. }
$$

3.3. Maximum Force on Rack $F_{\max }$. Due to the luffing effect, the arm frame elevation angle $\theta$ of portal crane can be changed within a certain range. By dividing the elevation range of arm frame into $N$ equal parts, a total of $(N+1)$ arm frame elevation angles $\left\{\theta_{1}, \theta_{2}, \theta_{3}, \ldots, \theta_{N+1}\right\}$ can be obtained. At the same time, the value of $F$ under a total of $(N+1)$ different arm frame elevation angles can be obtained, and then, the rack maximum force is

$$
F_{\max }=\max \left\{F_{\theta 1}, F_{\theta 2}, F_{\theta 3}, \ldots, F_{\theta(N+1)}\right\} .
$$

\section{Optimization of Pulling Point Position of Luffing Jib}

4.1. Original Design Parameters. As shown in Figure 4, this paper studies a port portal crane model, with an operating capacity of $9.5-33 \mathrm{~m}$, a lifting capacity $25 \mathrm{t}$ in the whole process, a height $50.4 \mathrm{~m}$ in nonworking dimensions, a portal gauge $10.5 \mathrm{~m}$, and a dead weight $417.3 \mathrm{t}$.

\subsection{Optimization of Mathematical Model}

4.2.1. Design Variable. The pulling point position of the rack is mainly optimized, so the optimal design variable is $\mathbf{x}=\left(x_{1}, x_{2}\right)$, where $x_{1}$ is the vertical distance from the hinge point of the rack to the arm frame and $x_{2}$ is the vertical distance from the hinge point of the rack to the rotation point of the arm frame. The unit of variables is $\mathrm{mm}$.

According to the existing design, the reasonable boundary of design variables is given:

$$
\begin{aligned}
& 1000<x_{1}<2500, \\
& 5500<x_{2}<7400 .
\end{aligned}
$$

\subsubsection{Constraint Condition}

(1) Angle between arm frame and horizontal line is $43<\theta<78$, and the unit of angle is degree.

(2) When the angle of the arm frame is at the maximum, the rack pulling point should not interfere with the buffer installed, so it needs to satisfy $x_{3}>1500$, and the unit of $x_{3}$ is $\mathrm{mm}$.

4.2.3. The Objective Function. The objective is to minimize the driving force required by the rack when the portal crane is lifting and luffing, in order to make the luffing mechanism more energy-saving and environment-friendly, so the objective function is 


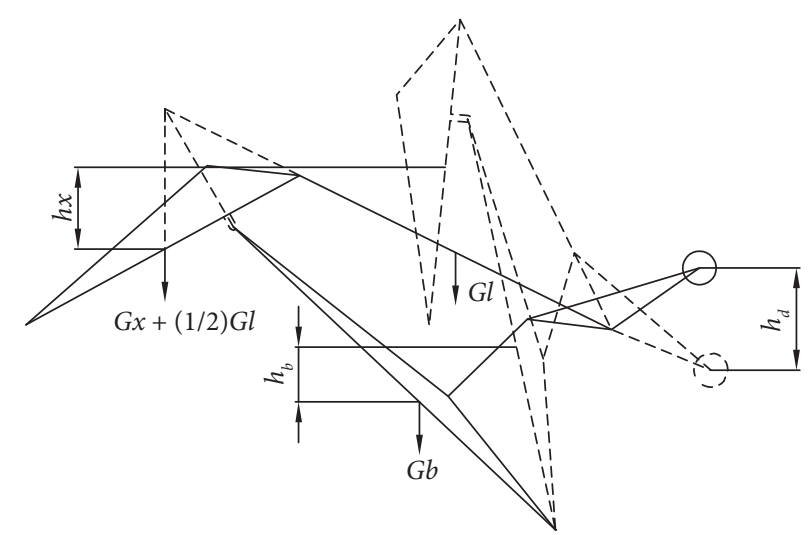

FIgURE 1: Schematic diagram of live counterweight-lever balance.

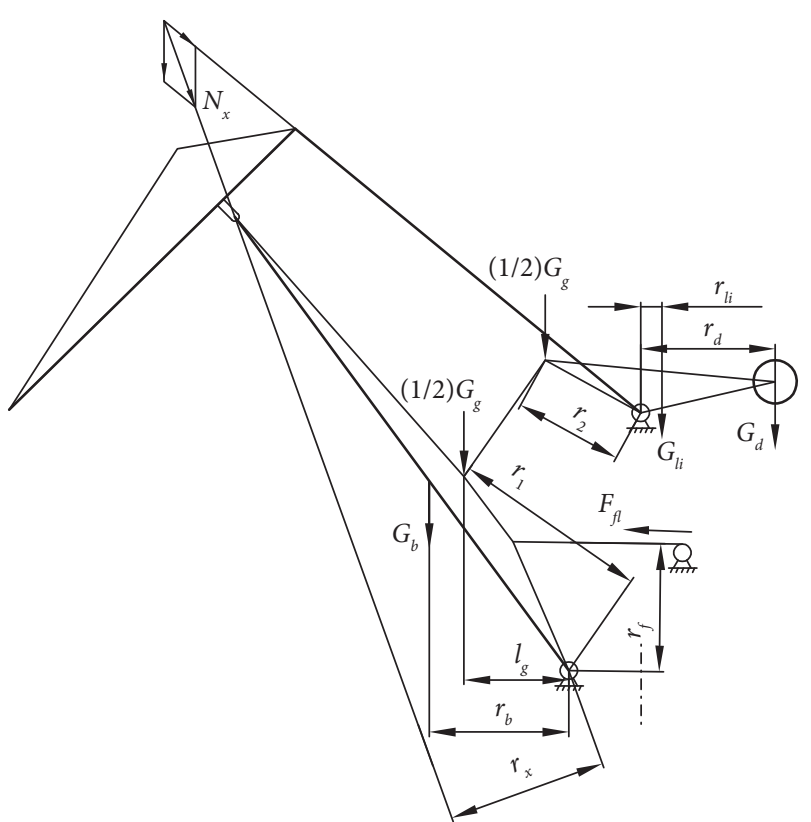

Figure 2: External load of jib system.

$$
f(\mathbf{x})=F_{\max }
$$

\section{Result Analysis}

The optimized results and the initial design results are shown in Table 1. Compared with the initial design scheme, the optimized maximum rack force $f(\mathbf{x})$ is reduced from $412 \mathrm{kN}$ to $397 \mathrm{kN}$, which is about $3.64 \%$ lower and has a certain optimization effect.

Figure 5 is the curve of rack pulling force of portal crane under different arm frame angles, and its horizontal coordinate is the elevation angle position after the arm frame angle is divided into 10 equal parts.

From Figure 5, it can be clearly seen that the rack pulling force tends to decrease first and then increase both the initial design and the optimized treatment, with the maximum value appearing at the position of maximum elevation angle (position 1 in the figure) and the minimum value appearing at around position 10 .

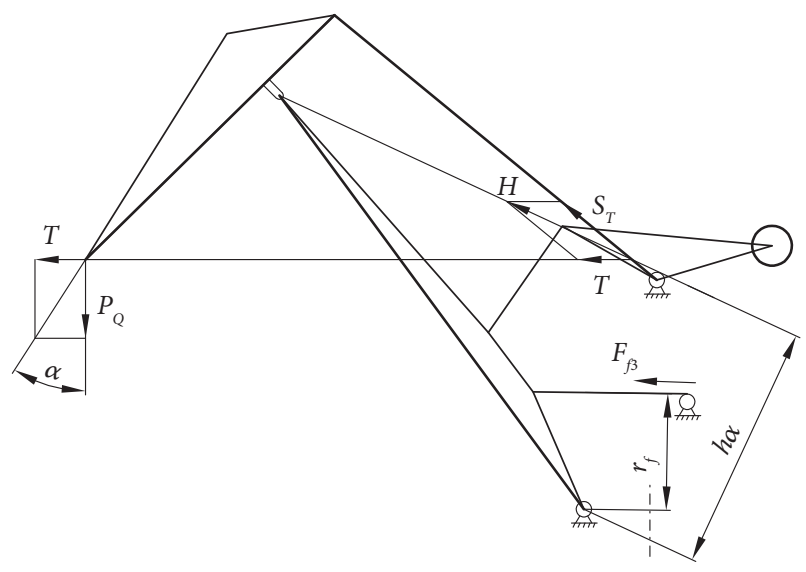

Figure 3: External load of jib system.

The optimized rack force is lower than the value before optimization under the elevation angle of each arm frame. For portal crane, the reduction in the overall rack pulling force in the crane luffing process makes the crane more energy-saving and environment-friendly.

The establishment of finite element model for simulation analysis can obtain a more real stress situation and verify the accuracy of the optimized design effect. Figures 6 and 7 show the maximum rack force and minimum rack force obtained by calculating in the process of crane luffing under different settings and sampling points $x_{1}$ and $x_{2}$, respectively.

From Figure 6, the trend of the maximum rack force with different $x_{1}$ and $x_{2}$ can be clearly known, where $x_{1}$ can cause a larger change in the maximum rack force. At the same time, it can be verified that the optimized maximum rack force is also at the lowest point of the whole curved surface, which is consistent with the results of finite element analysis.

Figure 7 shows that the minimum rack force of crane is greatly affected by the change in $x_{2}$. Since the objective function of the optimized design is the maximum rack force, the optimized minimum rack force cannot reach the minimum value in the whole range of design variables. However, compared with the initial design, the optimized minimum rack force is still lowered to a certain extent. 


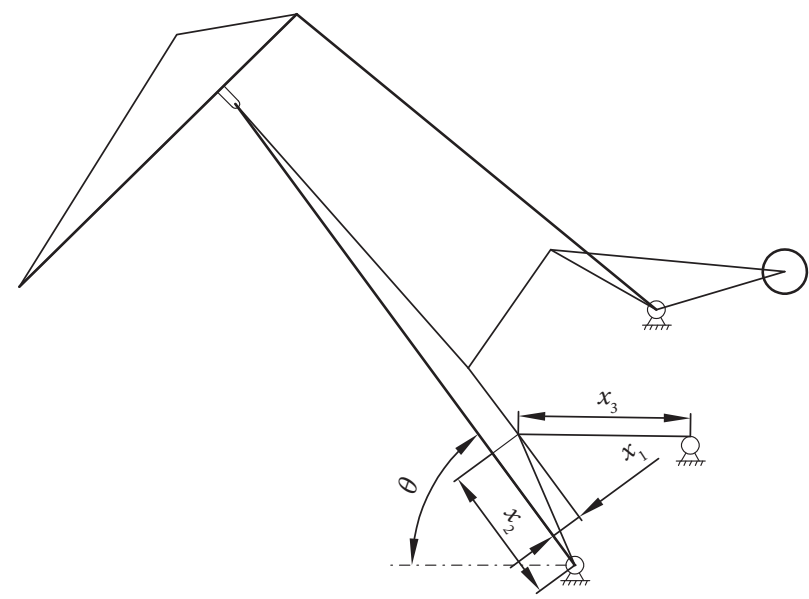

FIgURE 4: Structural diagram of portal crane.

TABLE 1: Comparison of optimization results with initial design.

\begin{tabular}{lcccc}
\hline \multirow{2}{*}{ Design scheme } & \multicolumn{2}{c}{ Design variables } & $\begin{array}{c}\text { Objective function } \\
f(\mathbf{x}), k \mathrm{~N}\end{array}$ & Optimum proportion \\
\hline Original & $x_{1}(\mathrm{~mm})$ & $x_{2}(\mathrm{~mm})$ & 412 & - \\
Optimized & 2178 & 6364 & 397 & $3.64 \%$ \\
\hline
\end{tabular}

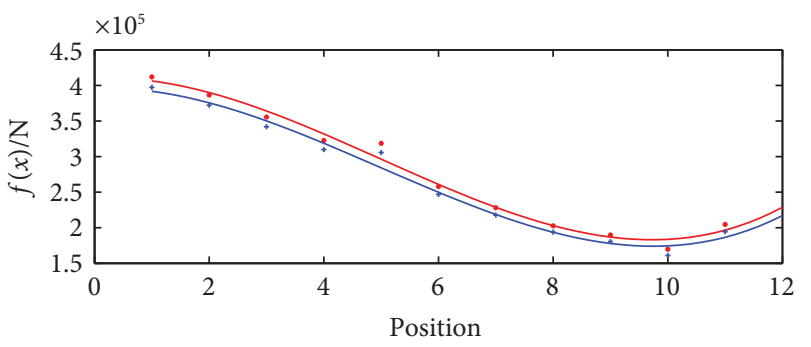

$$
\begin{aligned}
& \text { * } \\
& -
\end{aligned}
$$

FIGURE 5: Rack force at each position.

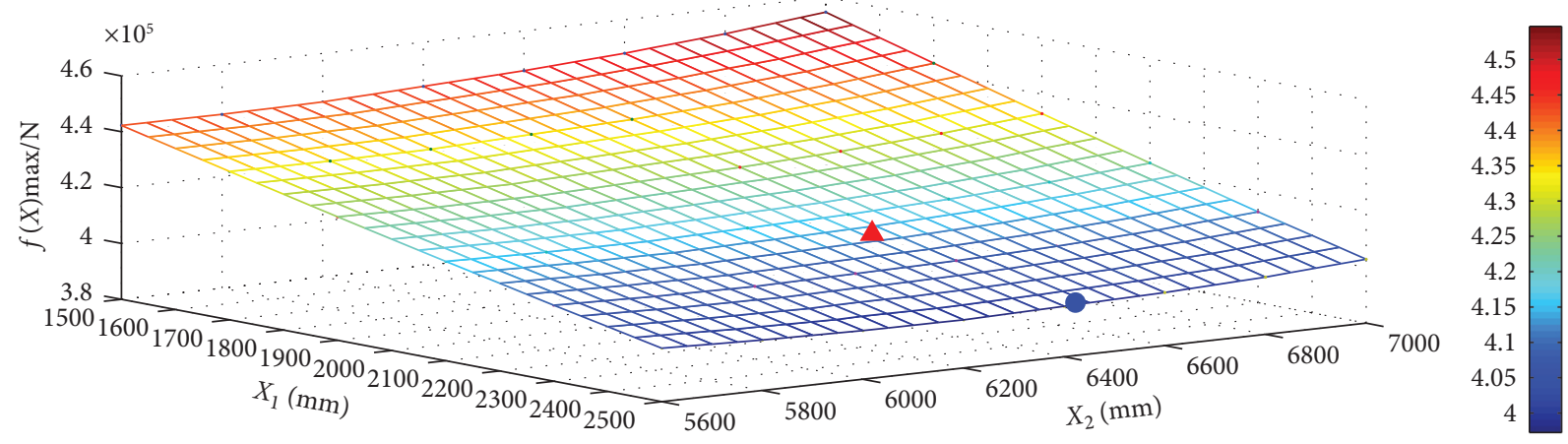

$\Delta$ Original

- Optimized

Figure 6: Maximum rack force $f(\mathbf{x})$. 


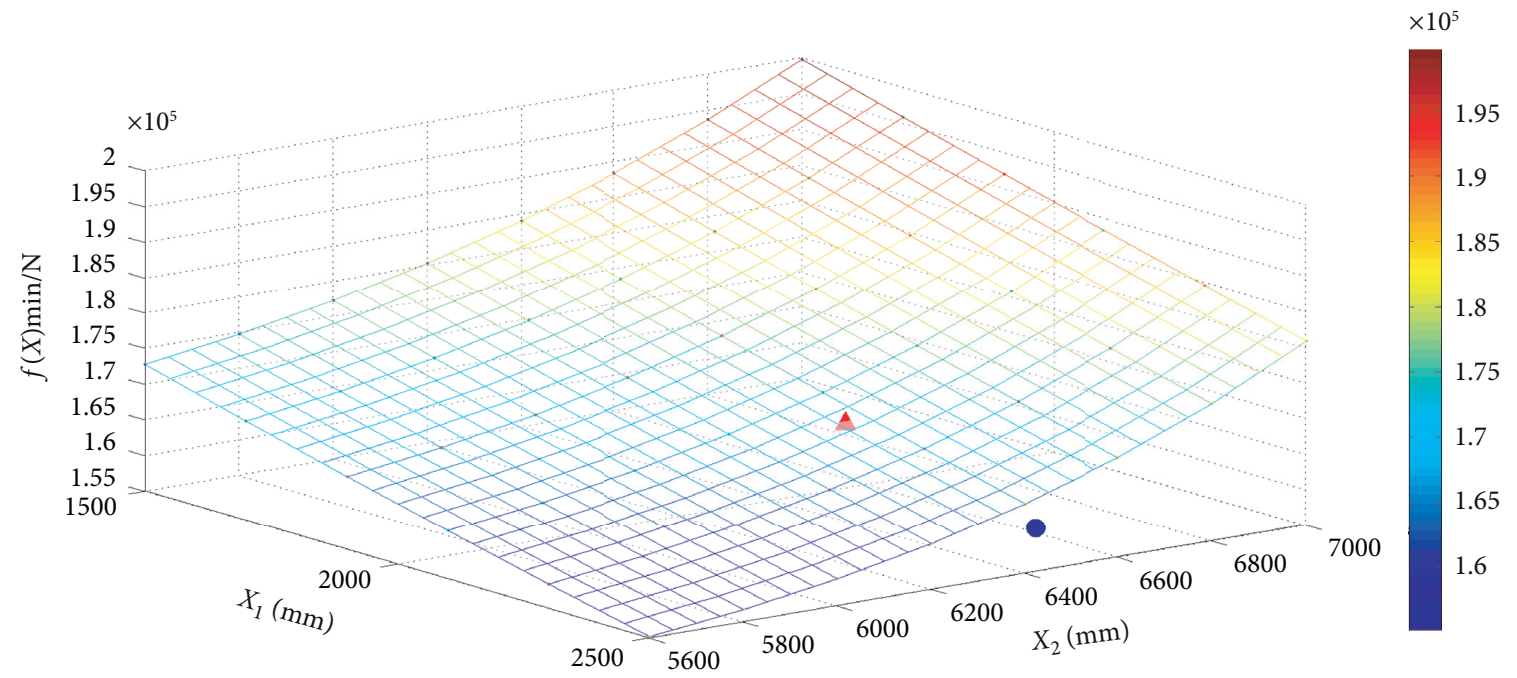

Original
Optimized

Figure 7: Minimum rack force $f(\mathbf{x})$.

\section{Conclusion}

By optimizing the luffing jib pulling point position of portal crane, the maximum rack force of portal crane can be reduced to the lowest value under the condition of full-load luffing of goods. At the same time, the lower minimum rack force under full load is also obtained, and a good optimization effect is obtained, thus saving the output of rack operation power consumption, simultaneously, making portal crane safer and more energy-saving and environment-friendly. The optimization results of the luffing jib pulling point position of portal crane are verified jointly with the finite element analysis results. Through finite element modeling and mechanical analysis, the effectiveness of the optimization results can be proved.

\section{Data Availability}

The data used to support the findings of this study are available from the corresponding author upon request.

\section{Conflicts of Interest}

The authors declare that there are no conflicts of interest regarding the publication of this paper.

\section{Acknowledgments}

This work was supported by the Fund for Shanxi "1331 Project" Key Subjects Construction (1331KSC) and the Shanxi Provincial Key Research and Development Project (201903D121067).

\section{References}

[1] S. Li, C. Wan, and Z. Hou, "Structural optimization research on superstructure of jib crane," Journal of the Brazilian Society of Mechanical Ences and Engineering, vol. 39, no. 7, pp. 1-9, 2017.

[2] X. Deng, G. Huang, A. Jiang, and S. He, "Research of portal crane vibration modal analysis," Automation and Information Engineering, vol. 93, pp. 277-282, 2016.

[3] L. Xu, "Simulation analysis about dynamic characteristics of four-bar linkage portal crane's jib based on the lifting loads," Sixth International Conference on Intelligent Systems Design and Engineering Applications (ISDEA), vol. 240, pp. 1-4, 2015.

[4] Z. H. Luo, "Optimization design for luffing mechanism of portal slewing crane," Applied Mechanics and Materials, vol. 577, pp. 305-309, 2014.

[5] Q. Zhao, S. Tong, W. Zhong, and J. Ge, "Optimal design of luffing mechanism of portal crane based on genetic algorithm and finite element analysis," Journal of Zhejiang University(Engineering Science), vol. 49, no. 5, pp. 880-886, 2015.

[6] S. C. Hu, S. Ouyang, N. B. Zou, and X. J. Wang, "The electromechanical coupling dynamics modeling and analysis of portal crane's hoisting system," Advanced Materials Research, vol. 952, pp. 210-215, 2014.

[7] D. Bauer, U. Schaper, K. Schneider, and O. Sawodny, “Observer design and flatness-based feedforward control with model predictive trajectory planning of a crane rotator," in Proceedings of the 2014 American Control Conference -ACC 2014 IEEE, pp. 4020-4025, Portland, OR, USA, June 2014.

[8] K. L. Li, L. L. Wang, N. Shan, and W. X. Tang, "Fea analysis for the trunk beam of the portal crane," Applied Mechanics and Materials, vol. 529, pp. 291-295, 2014.

[9] X. Zhu, J. Guo, and Z. Xie, "A dynamic weighing method for portal crane in bulk port: based on clustering and bp neural network," in Proceedings of the 2016 International Conference On Industrial Informatics Computing Technology, Intelligent Technology, Industrial Information Integration (ICIICII), pp. 22-25, Hubei, China, December 2016.

[10] Q. H. Tran, J. Huh, V. B. Nguyen, A. Haldar, C. Kang, and K. M. Hwang, "Comparative study of nonlinear static and time-history analyses of typical Korean STS container cranes," 
Advances in Civil Engineering, vol. 2018, Article ID 2176894, 13 pages, 2018.

[11] G. W. Qing, H. Jin, and J. B. Hu, "Simulation analysis of portal crane braking effect with dual-stage brakes under fluctuating wind load," Applied Mechanics and Materials, vol. 607, pp. 268-272, 2014.

[12] I. Kyung and S. Kwak, "Conceptual and basic designs of the mobile harbor crane based on topology and shape optimization," Structural and Multidisciplinary Optimization, vol. 50, no. 3, pp. 505-515, 2014.

[13] D. Kim and Y. Park, "3-dimensional position control scheme for mobile harbor crane," in Proceedings of the 2015 15th Interational Conference On Control,Automation And Systems (ICCAS 2015), pp. 2058-2061, Busan, Korea, October 2015.

[14] Y. Wang, H. Xiao, S. Lu, and M. Feng, "Dynamics simulation analysis of protal crane boom system based on adams," in Proceedings of the 2011 IEEE 2nd International Conference On Computing, Control And Industrial Engineering, pp. 290-292, Wuhan, China, October 2011.

[15] Y. Yang and H. Zhang, "Research on three-dimensional teaching mode of port machinery major based on virtual reality technology," in Proceedings of the International Conference on Education Technology and Computer, pp. 469-471, Malaysia, Kuala Lumpur, July 2010.

[16] Y. Weng and Y. M. Cheng, "Analysis of variable coefficient advection-diffusion problems via complex variable reproducing kernel particle method," Chinese Physics B, vol. 22, no. 9, pp. 201-206, Article ID 090204, 2013.

[17] X. J. Cai, M. J. Peng, and Y. M. Cheng, “An improved unitary Galerkin method for elastoplastic large deformation problems," China Science: physics, Mechanics, Astronomy, vol. 48, no. 2, pp. 57-66, 2018.

[18] R. J. Cheng and Y. M. Cheng, "Solving unsteady Schrdinger equation using the improved element-free Galerkin method," Chinese Physics B, vol. 25, no. 2, pp. 39-47, 2016.

[19] M. Peng and Y. Cheng, "A boundary element-free method (BEFM) for two-dimensional potential problems," Engineering Analysis with Boundary Elements, vol. 33, no. 1, pp. 77-82, 2009.

[20] Y.-M. Cheng, C. Liu, F.-N. Bai, and M.-J. Peng, “Analysis of elastoplasticity problems using an improved complex variable element-free Galerkin method," Chinese Physics B, vol. 24, no. 10, pp. 100202-100211, 2015.

[21] Y. X. Qin, W. T. Xie, H. P. Ren, and X. Li, “Crane hook stress analysis upon boundary interpolated reproducing kernel particle method," Engineering Analysis with Boundary Elements, vol. 63, pp. 74-81, 2016.

[22] Y. X. Qin, B. L. Li, X. Li et al., "Vibration analysis and control of nuclear power crane with MRFD," International Journal of Applied Mechanics, vol. 10, no. 8, pp. 1850093-1850101, 2018.

[23] R. Huang, S. J. Zheng, Z. S. Liu, and T. Y. Ng, "Recent advances of the constitutive models of smart materials hydrogels and shape memory polymers," International Journal of Applied Mechanics, vol. 12, no. 2, pp. 55-68, 2020.

[24] J. Cheng, "Analyzing the factors influencing the choice of the government on leasing different types of land uses: evidence from Shanghai of China," Land Use Policy, vol. 90, Article ID 104303, 2020.

[25] J. Cheng, "Data analysis of the factors influencing the industrial land leasing in Shanghai based on mathematical models," Mathematical Problems in Engineering, vol. 2020, Article ID 9346863, 2020.

[26] B. Nayroles, G. Touzot, and P. Villon, "Generalizing the finite element method: diffuse approximation and diffuse elements," Computational Mechanics, vol. 10, no. 5, pp. 307-318, 1992.

[27] R. A. Gingold and J. J. Monaghan, "Smoothed particle hydrodynamics: theory and application to non-spherical stars," Monthly Notices of the Royal Astronomical Society, vol. 181, no. 3, pp. 375-389, 1977.

[28] Y. X. Qin and Y. M. Cheng, "Reproducing kernel particle boundary element-free method for elasticity," Acta Physica Sinica, vol. 55, no. 7, pp. 3215-3222, 2006.

[29] P. P. Peng, Q. Wu, and Y. M. Cheng, "The dimension splitting reproducing kernel particle method for three-dimensional potential problems," International Journal for Numerical Methods in Engineering, vol. 121, no. 1, pp. 146-164, 2020.

[30] Q. Wu, P. P. Peng, and Y. M. Cheng, "The interpolating element-free Galerkin method for elastic large deformation problems," Science China Technological Sciences, vol. 63, pp. 1-11, 2020.

[31] F. X. Sun, J. F. Wang, Y. M. Cheng, and A. X. Huang, "Error estimates for the interpolating moving least-squares method in n -dimensional space," Applied Numerical Mathematics, vol. 98, pp. 79-105, 2015.

[32] Z. J. Meng, H. Cheng, L. D. Ma, and Y. M. Cheng, "The hybrid element-free Galerkin method for three-dimensional wave propagation problems," International Journal for Numerical Methods in Engineering, vol. 117, no. 1, pp. 15-37, 2019.

[33] Z. J. Meng, H. Cheng, L. D. Ma, and Y. M. Cheng, "The dimension split element-free Galerkin method for three-dimensional potential problems," Acta Mechanica Sinica, vol. 34, no. 3, pp. 462-474, 2018.

[34] Z. J. Meng, H. Cheng, L. D. Ma, and Y. M. Cheng, "The dimension splitting element-free Galerkin method for 3D transient heat conduction problems," Science China Physics, Mechanics and Astronomy, vol. 62, no. 4, pp. 49-60, 2019.

[35] L. Ma, Z. Meng, J. Chai, and Y. Cheng, "Analyzing 3D advection-diffusion problems by using the dimension splitting element-free Galerkin method," Engineering Analysis with Boundary Elements, vol. 111, pp. 167-177, 2020.

[36] R. J. Chen and Y. M. Cheng, "Error estimates of element-free Galerkin method for potential problems," Acta Physica Sinica, vol. 57, no. 10, pp. 6037-6046, 2008.

[37] Q. Wu, F. B. Liu, and Y. M. Cheng, "The interpolating element-free Galerkin method for three-dimensional elastoplasticity problems," Engineering Analysis with Boundary Elements, vol. 115, pp. 156-167, 2020.

[38] F. B. Liu and Y. M. Cheng, "The improved element-free Galerkin method based on the nonsingular weight functions for elastic large deformation problems," International Journal Of Computational Materials Science and Engineering, vol. 7, no. 3, pp. 1850023-1850031, 2018.

[39] S. Y. Yu, M. J. Peng, H. Cheng, and Y. M. Cheng, "The improved element-free Galerkin method for three-dimensional elastoplasticity problems," Engineering Analysis with Boundary Elements, vol. 104, pp. 215-224, 2019.

[40] B. H. Wang, Y. Q. Ma, and Y. M. Cheng, "The improved complex variable element-free Galerkin method for bending problem of thin plate on elastic foundations," International Journal of Applied Mechanics, vol. 11, no. 10, pp. 1212-1238, 2019.

[41] H. Cheng, M. J. Peng, Y. M. Cheng, and Z. J. Meng, "The hybrid complex variable element-free Galerkin method for 3D elasticity problems," Engineering Structures, vol. 219, no. 15, pp. 1-12, 2020. 
[42] R. Cheng and Y. Cheng, "Error estimates for the finite point method," Applied Numerical Mathematics, vol. 58, no. 6, pp. 884-898, 2008.

[43] N. Sukumar, T. Moran, and T. Belytschko, "The natural element method in solid mech anics," International Journal for Numerical Methods in Engineering, vol. 43, no. 5, pp. 839-887, 2015.

[44] B. D. Dai and Y. M. Cheng, "Local boundary integral equation method of radial basis function for potential problems," Acta Physica Sinica, vol. 56, no. 2, pp. 597-603, 2007.

[45] K. M. Liew and R. J. Cheng, "Numerical study of the threedimensional wave equation using the mesh-free $\mathrm{kp}$-ritz method," Engineering Analysis with Boundary Elements, vol. 37, no. 7-8, pp. 977-989, 2013.

[46] H. Cheng, M. J. Peng, and Y. M. Cheng, "The dimension splitting and improved complex variable element-free Galerkin method for 3-dimensional transient heat conduction problems," International Journal for Numerical Methods in Engineering, vol. 114, no. 3, pp. 321-345, 2018.

[47] H. Cheng, M. J. Peng, and Y. M. Cheng, "A hybrid improved complex variable element-free Galerkin method for threedimensional advection-diffusion problems," Engineering Analysis with Boundary Elements, vol. 97, pp. 39-54, 2018.

[48] H. Cheng, M. J. Peng, and Y. M. Cheng, "Analyzing wave propagation problems with the improved complex variable element-free Galerkin method," Engineering Analysis with Boundary Elements, vol. 100, pp. 80-87, 2019.

[49] Y. Tang and X. Li, "A meshless complex variable Galerkin boundary node method for potential and Stokes problems," Engineering Analysis with Boundary Elements, vol. 83, pp. 204-216, 2017.

[50] B.-D. Zhong, F. Yan, and J.-H. Lv, "Continuous-discontinuous hybrid boundary node method for frictional contact problems," Engineering Analysis with Boundary Elements, vol. 87, pp. 19-26, 2018.

[51] J. F. Wang and F. X. Sun, "A hybrid variational multiscale element-free Galerkin method for convection-diffusion problems," International Journal of Applied Mechanics, vol. 11, no. 7, pp. 1-23, 2019. 